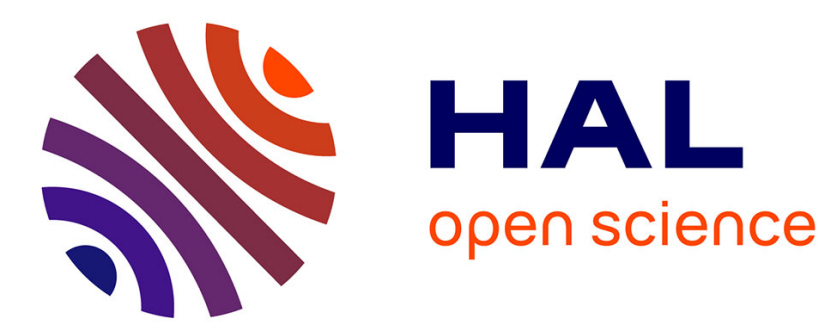

\title{
Numerosity Heuristic in Route Choice Based on the Presence of Traffic Lights
}

\author{
Blazej Palat, Patricia Delhomme, Guillaume Saint Pierre
}

\section{To cite this version:}

Blazej Palat, Patricia Delhomme, Guillaume Saint Pierre. Numerosity Heuristic in Route Choice Based on the Presence of Traffic Lights. Transportation Research Part F: Traffic Psychology and Behaviour, 2014, 22, pp 104-112. 10.1016/j.trf.2013.11.004 . hal-00921298

\section{HAL Id: hal-00921298 https://hal.science/hal-00921298}

Submitted on 20 Dec 2013

HAL is a multi-disciplinary open access archive for the deposit and dissemination of scientific research documents, whether they are published or not. The documents may come from teaching and research institutions in France or abroad, or from public or private research centers.
L'archive ouverte pluridisciplinaire HAL, est destinée au dépôt et à la diffusion de documents scientifiques de niveau recherche, publiés ou non, émanant des établissements d'enseignement et de recherche français ou étrangers, des laboratoires publics ou privés. 
Numerosity Heuristic in Route Choice Based on the Presence of Traffic Lights

Blazej PALAT (blazej.palat@ifsttar.fr) and Patricia DELHOMME

(patricia.delhomme@ifsttar.fr)

Laboratory of Driver Psychology (LPC), French Institute of Sciences and Technology for Transport, Development and Networks (IFSTTAR)

25 Allée des Marronniers Satory - F - 78000 Versailles, France

Guillaume SAINT PIERRE (guillaume.saintpierre@ifsttar.fr)

Vehicle-Infrastructure-Driver Interactions Research Unit (LIVIC), French Institute of Sciences and Technology for Transport, Development and Networks (IFSTTAR)

14 route de la Minière - Bâtiment 824 - Satory

78000 Versailles, France

Correspondance concerning this article should be addressed to Blazej PALAT, Tel : +331308439 53, Fax :+33130844001 


\begin{abstract}
We analyzed how the presence of traffic lights, as a cause of time loss, is taken into account by drivers in planning their route through urban areas. Our hypothesis was that routes with fewer traffic lights are preferred even if the probability of having to stop at those lights is high and the waiting time at the red light is long. We carried out a questionnaire-based study in which car drivers $(n=194)$ chose the route they preferred from pairs of hypothetical itineraries. The binary dependent variable was the type of route chosen: either a route containing fewer lights at which being forced to stop was highly probable, or a route containing more lights at which being forced to stop was far less probable. We found that the number of traffic lights was the preferred criterion, and that this preference could sometimes induce non-optimal route choices. Red- and green-light durations were also used as choice criteria. However, manipulation checks showed that participants did not estimate the probability of being forced to wait vs. being able to go through the light. We concluded that they estimated a threshold of acceptable waiting time at red lights depending on the number of traffic lights along the itinerary.
\end{abstract}

Keywords: route choice, traffic lights, information processing, traffic psychology 


\section{Introduction}

We are all so impatient that we believe there is often time to gain and especially not a minute to lose. When we are behind the wheel, this belief influences our choice of speed (Delhomme, 2002; Letirand \& Delhomme, 2003, 2005, 2006; Rothengatter, 1988). Several studies have shown that car drivers overestimate the time gained by driving at high speeds (Peer, 2010; Svenson, 2008, 2009), and that biased estimates of a journey's mean speed are more predictive of route choice than objective estimates (Svenson et al., 2011). In urban areas, however, car drivers generally have to deal with many interactions between different types of road users (trucks, motorcycles, cyclists, pedestrians, etc.) who are protected to various degrees and are moving at different speeds. Drivers cannot go too fast when their attentional resources are allocated to managing such interactions (Summala, 1997). In these circumstances, elements that can make a driver slow down or even stop have a substantial impact on travel time, which is why traffic lights are often considered by car drivers as a potential cause of time loss (Palat \& Delhomme, 2012; Porter \& Berry, 2001). It follows that drivers take traffic lights into account when planning their routes (Papinsky, Scott \& Doherty, 2009). Apparently, however, they do not necessarily use traffic-light information properly when choosing an itinerary.

The information to be taken into account by drivers who wish to optimize their travel time includes the number of lights they will encounter on their way and the duration of red and green lights (yellow-light duration is fixed at 3 seconds in built-up areas in France: Ministère de 1'Ecologie, de l'Energie, du Développement Durable et de la Mer, 2009). These pieces of information are usually available, although to various degrees of precision, for known itineraries. Every time a driver comes across a traffic light, it is likely that he/she will have to stop if the light is yellow or red. Knowing yellow-, red-, and green-light durations makes it possible to estimate the probability of having to stop at a traffic light. In fact, the 
three light colors delineate two periods in the cycle of a traffic light (Le Centre d'études sur les réseaux, les transports, l'urbanisme et les constructions publiques, 2008): a period during which approaching vehicles have to stop before the intersection (yellow and red lights) and a period during which approaching vehicles are authorized to go through the intersection (green light). When the two periods are equal in length, the probability of having to stop at the traffic light is $50 \%$. In reality, though, the yellow- and red-light duration is not always equal to the green-light duration, especially at intersections where the roads differ in size. When the redlight duration is longer than the green-light duration, the probability of having to stop at the traffic light increases, as does the average waiting time at the red light. Interestingly, red- and green-light durations are predictive of red-light running. In a study on car drivers' aggressive behavior (Shinar, 1998), the number of red-light violations was positively correlated with red-light duration, whereas it was negatively correlated with green-light duration.

Several criteria that could save time can be taken into account in choosing a route. Many car drivers consider the presence of traffic lights. The number of lights to be driven through during the trip, as well as the probability of having to stop at those lights (derived from red- and green-light durations) are important pieces of information. The driver should attach equal importance to both, and consider them simultaneously when estimating possible travel times. However, probability remains a relatively complex abstract concept for an average person even though in today's France, as well as in other industrialized countries, basics of probability theory are in the high school program (Ministère de l'Education nationale, 2011). Overwhelmed by information in everyday life, people routinely tend to engage in minimal cognitive processing when judging or making a decision (Fiske \& Taylor, 1984). Hence, decisions where probability judgments seem crucial are often biased because of heuristics used instead of probability estimations (Gilovich, Griffin, \& Kahneman, 2002; Sutherland, 1992). 
One such heuristic makes drivers pay more attention to the number of lights along an itinerary, especially when they allocate few cognitive resources to choosing a route. It is the numerosity heuristic, illustrated by Pelham, Sumarta, and Myaskovsky (1994). In their Study 4, an imaginary scenario was presented to students. A soldier had to choose between two minefields. There were fewer mines on the first minefield but the probability that they would explode was quite high. On the second minefield, there were more mines but the probability that they explode was lower. It was possible to estimate the probability that one could safely cross the first and the second minefields, $33 \%$ and $35 \%$, respectively. The participants skipped the calculation and chose the first minefield.

The possibility of focusing on number while overlooking other important criteria can be found in many common decision-making situations. Before taking the wheel or while already driving in a car, drivers often face similar dilemmas involving a choice between alternative routes. There are more traffic lights on certain itineraries than on others, but the probability of having to stop at the lights also varies across lights. It is plausible that drivers choosing a route with fewer traffic lights make the same mistake as the participants of the study described above. However, there are some important differences between the minefield problem and the route-choosing problem. The former is about a single success/failure probability in a complex repetitive-event situation, whereas the latter is motivated by the desire to avoid time loss caused by a number of stops more or less likely to occur. Route selection based on this last criterion can be modeled by the binomial distribution (the number of successes in a sequence of $\mathrm{n}$ independent Bernoulli experiments). In both cases, exact computations are quite difficult for a layperson. But the consideration of probabilities of single events can lead to correct decisions, especially for simple problems where the probability across the concerned events remains constant. In this case, there is a preference for 
using numerosity as a selection criterion rather than the probability of occurrence of a single event in a series.

The tendency to attach more importance to number can be explained within the framework of Cognitive-Experiential Self-Theory (CEST, Epstein, 1994). CEST is a dualprocess theory (for a review, see Chaiken \& Trope, 1999) and implies two modes of information processing: cognitive and experiential. The primacy of information on numerosity over probability judgments could be due to the preponderance of experiential information processing (EIP) in everyday life. Compared to cognitive information processing (CIP), EIP is influenced by emotions and past experiences. It is superficial, holistic, concrete, and proceeds by associations. Applying EIP is spontaneous and usually unconscious, contrary to applying CIP, which needs conscious mental effort. The two modes of information processing are not incompatible, but can result in conflicting tendencies. For instance, reasoned behavior often gives way to emotion-driven impulsive behavior in everyday life.

The ratio bias paradigm (Kirkpatrick \& Epstein, 1992) perfectly illustrates the conflict resulting from these two types of information processing. Participants in the Kirkpatrick and Epstein experiment could win money if they drew a winning ticket out of two bowls. The proportion of winning tickets was the same in each bowl, but one bowl contained more tickets than the other. The majority of the participants preferred to draw from the bowl where there were more tickets, i.e., where winning tickets were more numerous. The most astonishing finding was that the participants were aware of the irrationality of their behavior, yet incapable of ignoring numerosity. The bias was observed even when the proportion of winning tickets was lower in the bowl containing a greater absolute number (Denes-Raj \& Epstein, 1994). If drivers really do base their route choice on the number of lights rather than on probabilities of stopping on each light, the ratio bias might help in understanding the cognitive underpinnings of this preference. 
The primacy of numerosity estimations over probability judgments in decision making could be a consequence of people's understanding of probability. In everyday life, probability estimation is derived from the perception of the frequency of occurrence (Estes, 1976). Perceived frequency of occurrence is based on the ability to estimate the number of times an element is repeated in a period of time. The greater the frequency at which the occurrence of an event was observed in the past, the more probable its occurrence in the future is judged to be. Human beings, like animals such as rats or pigeons, have a high degree of sensitivity to the frequency of occurrence of events (Gallistel, 1989). By the age of 4.5 months, human infants can integrate information concerning both the frequency and conditional probability of the appearance of geometrical shapes in a sequence (Marcovitch \& Lewkowicz, 2009). It is probably because information about the frequency of occurrence is automatically processed by the central nervous system (Hasher \& Zacks, 1984).

It is therefore not surprising that in circumstances where probability cannot be directly deduced from perceptions about the frequency of occurrence of an event, perceived frequency of occurrence can hinder probability judgments. This phenomenon was well demonstrated by Estes (1976, Experiment 1). Several analogies can be drawn between the findings of his study and route selection based on consideration of repeatedly going through traffic lights. Recall that two factors are to be taken into account in the desire to save time: the number of traffic lights - as an indication of the frequency of occurrence of those lights during the trip - and the probability of having to stop at each of those lights. Studies based on the ratio bias paradigm (Denes-Raj \& Epstein, 1994; Kirkpatrick \& Epstein, 1992) show that probability estimations may be correct, but they may not be taken into account in decision-making whenever a more salient and more accessible criterion such as numerosity is present. We can therefore expect drivers to choose routes with fewer traffic lights, independently of the perception of a high probability of having to stop at those lights, or that their probability judgments will be biased 
if the frequency-of-occurrence criterion (i.e., the number of traffic lights to be gone through on a route of a given length) implies a solution contrary to that implied by the probability criterion (derived from red- and green-light durations).

We can assume, then, that when choosing between two routes, drivers will prefer a route with fewer traffic lights where the probability of having to stop is high, to a route with more traffic lights where the probability of having to stop is low. In doing so, drivers would focus on numerosity and overlook probability when they are making a time-saving choice. This tendency would result in a number of non-optimal route choices from the time-saving point of view.

2. Method

\subsection{Participants}

The participants in the research were 194 college students (87 males and 106 females), averaging $21.4(s=3.28$, range: $18-46)$ years of age, recruited on a campus of a regional university and two universities from the France's capital city. They had had their car driver's license for 2.3 years on average ( $s=2.94$, range: 2 months-24 years), and drove an annual average of 1,786 ( $s=1,256$, range: 500-22,500) kilometers by car.

\subsection{Procedure}

The experimenter asked students to participate in a study aimed at exploring the diversity of car drivers' opinions and behaviors. The lead author met students on university campuses, in building halls, cafeterias, and in outdoor areas around the buildings. Only those who declared having their car driver's license participated in the study which was anonymous. The questionnaire was administered individually and took between 10 and 15 minutes to be filled in. 


\subsection{Questionnaire}

The questionnaire was devised on the basis of a literature review and interviews with car drivers. The preliminary version was pre-tested during a university course by 50 psychology students (mean age: 20.9 years, $s=4.78$, range: 18-52) who had had their car driver's license for 1.94 years on average ( $s=3.2$, range: 2 months- 22 years and 9 months), and drove an annual average of 7,207 ( $s=7,379$, range: 500-22,500) kilometers by car. The pretest made it possible to enhance the questionnaire. The final questionnaire had four sections. The first was aimed at testing the use of information concerning the frequency of occurrence of traffic lights vs. the probability of having to stop at the lights, for choosing a route in a hypothetical situation. The second part was aimed at gathering information about the how participants planned their routes for car trips in everyday life. This part contained measures of the frequency at which alternative itineraries were considered, and the frequency at which the number of traffic lights, red-, and green-light durations were taken into account in route choice. The third part contained measures of the driver's characteristics. The fourth part contained manipulation checks aimed at testing to see if participants correctly recognized the probability of having to stop vs. go through traffic lights derived from red- and green-light durations.

Most measures were in the form of multiple-choice questions and five-point Likert scales. The measures of behavior frequencies used scales ranging from 1 (never) to 5 (often).

\subsubsection{Frequency of Traffic Lights vs. Probability of Losing Time at Lights}

The aim of this measure was to verify which criterion would be preferred by participants making a route choice in a hypothetical situation. The criteria under consideration were the number of traffic lights on a given itinerary (the number of lights makes it possible to infer their frequency of occurrence), and the probability of having to stop vs. go through the lights (to be inferred from red- and green-light durations). The participants had to choose 
the itinerary they preferred for each of 15 pairs of itineraries presented on the questionnaire. All itineraries had the same distance to cover $(20 \mathrm{~km})$ and went through a built-up area. However, in each pair, there was one itinerary containing more traffic lights with a low stopping probability, and one itinerary containing fewer traffic lights with a high stopping probability. The presentation order of the itineraries within each pair and the presentation order of the pairs were randomized. The following instructions were given to the participants: Imagine yourself having to travel 20 kilometers by car through a built-up area. Below you will find pairs of alternative itineraries for your trip (for example, Itinerary $1 \mathrm{~A}$ and Itinerary 1B). Both itineraries contain a certain number of traffic lights, which have specific red- and green-light durations. In each pair of itineraries, indicate which one you prefer by putting an " $\mathrm{x}$ " in the box corresponding to your answer.

In each pair, there was one itinerary with 12 traffic lights and one itinerary with less than $12(4,5,6,7$, or 8 lights). For the itineraries with 12 traffic lights, the red-light duration was always shorter than the green-light duration, and conversely, for itineraries with fewer traffic lights the red-light duration was always longer than the green-light duration. The shorter (red- or green-light) duration was always $20 \mathrm{~s}$, and the longer duration was 40,50 , or $60 \mathrm{~s}$. Therefore, there were five conditions of the difference between the numbers of traffic lights within the itineraries $(12-4,12-5,12-6,12-7,12-8$ lights $)$, and three conditions of the difference between red- and green-light durations (20-40, 20-50, 20-60 s) (see Table 1). The number of traffic lights, as well as green- and red-light durations were chosen arbitrarily so as to obtain clearly distinguishable pairs with a varying spread between the number of traffic lights and between green- and red-light durations.

[Insert Table 1 here]

This study offers a schematic illustration of choosing between an itinerary leading through big arteries and an itinerary leading through secondary streets. Traffic lights are 
frequent along the main streets in urban areas, but they are set so as not to overly limit the flow of vehicles, which is greater than in secondary streets. However, our approach does not take "green waves" into account which may be set up along important arteries. Such traffic-light synchronization exists in French cities but is not always the rule. Therefore, we decided not to take this factor into consideration so as to limit the number of route-choice criteria. Last but not least, we included the yellow-light duration in the red-light duration because drivers are required to stop at yellow lights too.

For the purposes of our study, it was necessary to accurately estimate the mean time spent waiting at red lights for all itineraries, in order to evaluate the participants' choices from the point of view of time saving. All itineraries were of equal length. However, in each pair of itineraries the number of traffic lights and the red- and green-light durations varied. A theoretical estimation of the waiting time along a given itinerary is too complex, but it is possible to simulate it to obtain a sufficiently accurate estimate. The simulation was carried out in R programming language. As explained above, we assumed that the lights were not synchronized, so a random drawing was performed as many times as there were traffic lights to pass through along a given itinerary. The outcome could be red light or green light, and the probability of drawing one of these depended on the red- and green-light durations. When the outcome was a green light, the waiting time was set at 0 . When the outcome was a red light, the waiting time was a randomly chosen value between 0 and the entire red-light duration for a given itinerary. Waiting times at each light were summed so as to obtain the total waiting time during the trip. This procedure was repeated 100,000 times for each of 30 itineraries on the questionnaire, which gave us estimates of the mean waiting time and the mean number of stops. It also gave us an estimate for each pair of the predicted relative frequency of one itinerary being faster than the other and the predicted relative frequency of the number of stops being lesser on one itinerary comparing to the other. Those two latter estimates were 
$\underline{\text { used as objective criteria for judging the participants' preferences for itineraries within each }}$ pair. The predicted relative frequency of one itinerary being faster than the other pertained to the time saving criterion. The predicted relative frequency of the number of stops being lesser on one itinerary comparing to the other pertained to the criterion of maintaining driving fluency.

\subsubsection{Itinerary Planning}

The participants were asked how often they thought about alternative itineraries before taking the wheel, and while driving. They were also asked how often they used the number of traffic lights on the itinerary, as well as red- and green-light durations at traffic lights, as criteria for choosing an itinerary in real-life driving situations. The responses to these four questions were frequency ratings.

\subsubsection{Driver Characteristics}

The participants reported the number of yellow and red lights they had deliberately run during the month prior to the study. This number was an approximation and had to be chosen from a scale composed of six ranges defined as follows: 0-1, 2-3, 4-5, 6-7, 8-9, and 10 or more. Two separate questions were given, one concerning yellow lights and one concerning red lights.

They also reported whether they observed speed limits in urban areas, on undivided highways, and on divided highways, on 5-point Likert scales ranging from 1 (not at all) to 5 (absolutely). Given their strong consistency $(\alpha=0.75)$, the mean of these three estimations was used as a single measure of abidance by speed limits.

Finally, the participants reported their age, sex, date of obtaining their automobile driver's license, and the annual number of kilometers driven by car. This number was an approximation and had to be chosen from a scale composed of six ranges defined as follows: 
less than 1,000 km, between 1,001 and 4,999 km, between 5,000 and 9,999 km, between 10,000 and 14,999 km, between 15,000 and 19,999 km, and 20,000 km or more.

2.3.4. Control Measure Aimed at Testing Estimation of the Probability of Having to Stop at Traffic Lights

In order to test perceptions regarding the probability of being forced to stop at traffic lights during the itineraries presented in the questionnaire, a problem about two hypothetical lights (A and B) was given to the participants. Each light was described by its red-and green-light durations. The red-light duration of A was 40 seconds, while the red-light duration of B was 60 seconds. The green-light duration at both traffic lights was always 20 seconds. The participants had to indicate which traffic light they thought involved a greater probability of having to stop, or whether this probability was equal at the two lights. They gave their response by putting a "<", ">”, or "=" sign between traffic lights A and B. The objectively estimated probability of having to stop at light A was 0.67 ; it was 0.75 at light B.

3. Results

The choice of an itinerary with a number of traffic lights below 12 was interpreted as a choice based more on the number of traffic lights. For further analysis, the sum of numberbased choices was used as an individual score measuring the use of information about the number of traffic lights. The score was distributed normally $(D=0.12, p<.13)$, and had a mean of $8.73(s=3.7, \min =0, \max =15)$. Descriptive statistics of self-reported measures used in the analyses are given in Table 2.

[Insert Table 2 here]

\subsection{Using Traffic-Light Information to Choose an Itinerary}

In order to test the criteria of participants' route choice, we used Generalized Estimation Equations (GEE, Liang \& Zeger, 1986). Compared to logistic regression, which is often employed to make predictions of binary variables, the advantage of GEEs is that they 
make it possible to analyze repeated-measures data by taking into account marginal correlations between measures, for example, on a single subject. In our analysis, we chose to use an exchangeable covariance structure because we did not expect any important differences between the correlations of individual measures (Agresti, 2002). For each pair, the GEE model also provide us with a probability estimation that the itinerary with fewer traffic lights would be chosen within a given pair. The advantage of the estimate obtained by the GEE model over an estimate obtained simply by the relative frequency of participants' choices was that the former accounted for the random effect due to repetitive measures. Our aim was to test whether the participants used the information concerning the number of traffic lights and the red-, and green-light durations, or whether the salience of one of these types of information affected the use of the other. Another aim was to test whether participants' choices were influenced by the extent to which they were experienced in planning itineraries and by the criteria pertaining to traffic lights that they used when choosing an itinerary in everyday life driving situations. Therefore the variables included in the model as predictors of the choice between two alternative itineraries were: difference between the numbers of traffic lights within pairs, difference between red- and green-light durations (cf. Section 2.3.1), and $\underline{\text { the interaction between these two factors; the two self-reported measures of frequency of }}$ planning alternative itineraries, and the two self-reported measures of frequency of use of information concerning traffic lights (cf. Section 2.3.2).

Values of $\chi^{2}$ tests give a measure of predictors' effect size and their relative levels of $\underline{\text { significance. Values of } Z \text { statistic are given for linear predictors in order to show the direction }}$ of the linear relationship between a linear predictor and the binary dependent variable (the $\underline{\text { choice of an itinerary with more traffic light was coded } 1 \text { and the choice of an itinerary with }}$ less lights was coded 0). The results of the analyses showed that the route choices were made on the basis of the number of traffic lights $\left(\chi^{2}=127.56, p<.001\right)$, but also on red- and green- 
light durations $\left(\chi^{2}=95.36, p<.001\right)$. Moreover, there was an interaction between these two types of information $\left(\chi^{2}=17.21, p<.028\right)$ which indicated that the smaller was the difference between the numbers of traffic lights within itineraries forming a pair, the more influence on the route choice had the information concerning traffic-light durations (cf. Table 3). In addition, the route choice in hypothetical situations depended on the self-reported frequency of using the number of traffic lights $\left(\chi^{2}=12.79, p<.001 ; Z=-4.63, p<.001\right)$, as well as redand green-light durations $\left(\chi^{2}=14.51, p<.001 ; Z=4.13, p<.001\right)$ as criteria for route choice in real-life driving situations. The participants who reported using the number of traffic lights as a criterion for route choice in real-life driving situations more frequently were more likely to choose itineraries with less traffic lights, while the participants who reported using the red$\underline{\text { and green-light durations as a criterion for route choice in real-life driving situations more }}$ frequently were more likely to choose itineraries with more traffic lights (and therefore shorter red-light durations). However, the participants' preferences did not depend on the selfreported frequency of planning alternative itineraries either before taking the wheel $\left(\chi^{2}=0.4\right.$, $p<0.53 ; Z=0.66, p<0.51)$ or while already driving $\left(\chi^{2}=0.59, p<0.44 ; Z=-0.79, p<0.43\right)$. We can therefore conclude that in this experimental task the participants used route-choice criteria pertaining to the traffic lights in the same way they reported using them in real-life driving situations, and that their choices did not depend on the level of experience in planning itineraries.

Finally, for each pair, we analyzed the probability of choosing an itinerary, and the probability that this choice could yield a desirable outcome such as minimization of waiting time and stops (cf. Table 3). The probability of choice was estimated by the GEE model, the probabilities that choosing an itinerary could result in minimization of waiting time and the number of stops were given by the predicted relative frequencies obtained by simulation (cf. Section 2.3.1.). If participants had known the probability of spending less time waiting at red 
lights along each itinerary (summing to 1), the optimal choice would have consisted of choosing the itinerary where this probability was above 0.5 . However, in our experimental setting, choices were made under uncertainty. We therefore assumed that the participants used available information in order to estimate the chances of obtaining a time gain or stop less when choosing an itinerary. In the situations where the two itineraries were nearly equivalent from the standpoint of time saving, but where one of them was more likely to be chosen (Pairs 3, 5, and 7; over a light-grey background in Table 3), the participants exhibited a preference for a particular criterion that influenced decision-making (here, the number of traffic lights), although we cannot say that this preference was likely to cause non-optimal choices (choices of an itinerary that offered a time-gain probability below 0.5 ). However, situations where one itinerary had a lower probability (below 0.5 ) of being the time-saving option and participants still hesitated or preferred this itinerary (probability of choosing the itinerary was greater than or equal to 0.5 , Pairs 6, 8, 10 and 13, over a dark-grey background in Table 3), indicated that the preference for the number of traffic lights as a criterion for route choice could also induce non-optimal choices. Moreover, in these situations participants were also likely to make non-optimal choices from the standpoint of possible number of stops.

[Insert Table 3 here]

\subsection{Manipulation Checks}

\subsubsection{Estimation of Probability of Having to Stop at Traffic Lights}

Traffic light B was correctly identified by 146 (75.3\%) participants as the light where the probability of being forced to stop was higher, which means that a non-negligible number $(48,24,7 \%)$ of participants were incapable of inferring the stopping probability from the information on traffic-light duration. Nonetheless, an analysis of variance (ANOVA) did not yield a significant difference between the participants who gave the correct answer and those who gave an incorrect answer with respect to the use of traffic-light information as the 
criterion for route choice in the hypothetical situations $(M=8.6, s=3.65$, and $M=9.13$, $s=3.87$, respectively, $F=0.74, p<.39$ ). Hence, the data from the entire sample was kept for the analyses.

\subsubsection{Test of Relationships Between the Criteria Used to Choose an Itinerary and}

\section{Observing Road Rules}

Assuming that certain drivers could have chosen itineraries with fewer traffic lights in order to limit obstacles to speeding, or with more traffic lights but while counting on going through yellow or red ones on several occasions, we tested the relationship between the choices made in hypothetical situations and the self-reports of these two kinds of violations. The score for the use of traffic-light information was regressed on the self-reported measures of yellow- and red-light running, and of speeding. This analysis yielded no significant results. Therefore, we considered that participants' unruly behavior behind the wheel did not influence their route choice in the hypothetical choice situations.

\section{Discussion}

We hypothesized that the number of traffic lights along a route would be used as a route-selection criterion rather than the probability of being forced to stop at lights. In order to test this hypothesis, we built pairs of alternative itineraries of the same length, but which had different numbers of traffic lights and variable probabilities of forcing the drivers to stop at those lights. As expected, when information concerning red- and green-light durations and the number of traffic lights was available, the information about the number of lights was the most important criterion for route choice. The preference for this piece of information was also likely to increase the possibility of a non-optimal choice from the point of view of time saving.

One could argue that time saving might not be the only reason for choosing an itinerary with fewer traffic lights. In fact, traffic obstructions elicit negative emotional 
reactions such as frustration (Shinar, 1998) and anger (Deffenbacher, Oeting, \& Lynch, 1994). The decision to avoid traffic lights on one's itinerary could therefore be considered as not entirely rational. From this angle, stopping even for a brief period of time seems undesirable. Drivers who have this attitude would not reason in terms of minimizing time loss, but in terms of minimizing the number of stops. They could still have used the information about red- and green-light durations to infer stopping probability. This seems unlikely, given that the itineraries with fewer lights were chosen on several occasions where they could not be considered optimal from the standpoint of limiting the number of stops.

Continuing this line of reasoning, we can assume that there were participants who were more or less motivated to save time. Those who were less motivated to save time preferred the more pleasant alternative: an itinerary with fewer stops. Those who were strongly motivated may have acted like gamblers by trying to apply a strategy that maximized their chances of picking the alternative that would lead to the desirable outcome. This strategy made use of the information about red- and green-light durations.

However, our manipulation checks showed that red- and green-light duration information was not used for the probability judgments (the response pattern was the same for those participants who had not perceived the correct probability and those who had). It could be that the drivers referred to their real traffic-light experience rather than to abstract speculations. The salience of information from past experiences is characteristic of EIP (Epstein, 1994). The presence of a traffic light is salient insofar as a red light is perceived as an obstacle. We therefore believe that the participants referred to their previous experiences of waiting at red lights (Tenenbaum, Kemp, Griffiths, \& Goodman, 2011). They acted as if they had to stop at each traffic light on that route, and then used the red-light duration information to determine a threshold of acceptable waiting time depending on the number of traffic lights along the way. Itineraries with fewer traffic lights were generally preferred. Nonetheless, 
when the difference between the number of traffic lights on each route in a pair diminished, the information provided by red-light duration became more important and the threshold of acceptable red-light waiting time went down, making the itineraries with more lights (but shorter red-light durations) more attractive. This explanation can only be taken as an exploratory hypothesis and needs further research to be confirmed.

The salience of the experience of waiting at a red light may have been reinforced by another phenomenon. This brief moment may be perceived as a time loss independently of total travel time. At a red light, the driver has to watch the light (or/and the vehicle in front) while waiting. He/she cannot get distracted or do anything else during that time, at the risk of blocking other road users when the light turns green again. This is a situation of prospective time evaluation, like any other waiting experience (Zakay \& Block, 1997; Zakay, 2005). A driver's attentional resources are more available, which increases his/her sensitivity to the passage of time, unlike other driving situations where attention is more involved and time passes relatively unnoticed (Block, Hancock, \& Zakay, 2010).

One possible reason for paying attention to red-light duration could be traffic density and traffic-jam formation at traffic lights, where red lights seem particularly long. Participants could have taken this factor into account implicitly even if it was not mentioned in the instructions. Here again, they may have referred to their real-life driving experiences. Indeed, prolonged waiting at a traffic light may be considered frustrating, especially during periods of traffic congestion when the waiting time at a traffic light may exceed one red-light cycle (Shinar, 1998).

The practical conclusions of our study concern drivers' perceptions of traffic lights. A traffic light will always be considered as a potential obstacle that should be avoided, even if avoiding it does not make the total travel time shorter. This is an argument against the overuse of traffic lights by traffic management departments. This risk particularly concerns big cities 
with dense road networks and heavy traffic. We believe that the excess of traffic lights could be removed. Respecting the rule of priority to the right and priority to pedestrians on crosswalks would have been sufficient for avoiding car and pedestrian crashes in many locations where traffic lights are now regulating the traffic flow. A better evaluation of the needs for traffic regulation could help identify these locations. Removing redundant traffic lights could contribute to create an urban environment where drivers who tend to avoid traffic lights in general could make more optimal route choices. Furthermore, we also believe that it could make drivers less used to rely on traffic lights for deciding whether to yield the right-ofway. Therefore, they would become more attentive to the right-of-way rules mentioned above at sites of conflicting traffic with no traffic lights. However, this issue is beyond the scope of the present study.

As for the limitations of this study, we based our approach on self-report measures, and we used a schematic simplification to present alternative itineraries to participants. Our setup was made to fit an experimental design. Hence, we moved away from the real context of choosing an itinerary even if we effectively found some evidence that there were indeed relationships between the criteria participants used to choose a route in hypothetical and real situations. Experience with GPS guidance is an issue that was not investigated in our questionnaire. Drivers may become increasingly dependent on GPS for route choice in coming years. We believe that its use will limit the scope of criteria taken into account for route choice at least for unknown itineraries. Otherwise, for itineraries which characteristics are known (the number of traffic lights, for example) drivers would continue to rely on their own judgment or previous experiences. Nonetheless, future research on heuristics applied for route choice will have to take GPS use into consideration. Last but not least, our questionnaire was filled in by college students. Therefore, the generalizability of the results seems effectively limited. Future work will also have to use a more diversified sample of car drivers. 
Another limitation concerns emotional factors, which were not taken into account in the present study but could also make the number of traffic lights an important criterion in route selection. A traffic light can be a source of stress, insofar as watching the light generates a cognitive load (Hoyos, 1988) and also creates uncertainty over which the driver has no control (Averill, 1973; Pervin, 1963). Therefore it can be argued that at least for certain drivers the greater number of traffic lights could contribute to a greater driving stress.

In future research, the use of information about traffic lights in choosing an itinerary should be tested with a method based more on behavioral measures in real contexts or in simulated driving situations. These approaches should make it possible to introduce several complementary measures aimed at testing the influence of factors related to driving that were not considered in the present study. These experimental approaches could also make it possible to find out whether perceptions of total travel time are distorted by perceptions of time spent waiting at red lights. 


\section{References}

Agresti, A. (2002). Categorical data analysis. John Wiley \& Sons, Hoboken.

Averill, J. (1973). Personal control over aversive stimuli and its relationship to stress. Psychological Bulletin, 80, 286-303.

Block, R. A., Hancock P. A., \& Zakay, D. (2010). How cognitive load affects duration judgments: A meta-analytic review. Acta Psychologica, 134, 330-343.

Chaiken, S., \& Trope, Y. (Eds.). (1999). Dual-process theories in social psychology. Guilford Press, New York.

Deffenbacher, J. L., Oetting, E. R., \& Lynch, R. S. (1994). Development of a driving anger scale. Psychological Reports, 74, 83-91.

Delhomme, P. (2002). Croyances des jeunes automobilistes en matière de vitesse [Young car drivers' beliefs about speed] (Final report. Convention DSCR-INRETS N00/010/TStudy n7). INRETS, Arcueil.

Denes-Raj, V., \& Epstein, S. (1994). Conflict between intuitive and rational processing: When people behave against their better judgment. Journal of Personality and Social Psychology, 66(5), 819-829.

Epstein, S. (1994). Integration of the cognitive and psychodynamic unconscious. American Psychologist, 49(8), 709-724.

Estes, W. K. (1976). The cognitive side of probability learning. Psychological Review, 83(1), $37-64$.

Gallistel, C. R. (1989). Animal cognition: The representation of space, time and number. Annual Review of Psychology, 40, 155-189.

Gilovich, T., Griffin, D., \& Kahneman, D. (2002). Heuristics and biases: The psychology of intuitive judgment. Cambridge University Press, Cambridge. 
Hasher, L., \& Zacks, R. T. (1984). Automatic processing of fundamental information. The case of frequency of occurrence. American Psychologist, 39(12), 1372-1388.

Hoyos, C. G. (1988). Mental load and risk in traffic behaviour. Ergonomics, 31(4), 571-584.

Kirkpatrick, L. A., \& Epstein, S. (1992). Cognitive-experiential self-theory and subjective probability: Further evidence for two conceptual systems. Journal of Personality and Social Psychology, 63(4), 534-544.

Le Centre d'études sur les réseaux, les transports, l'urbanisme et les constructions publiques (CERTU). (2008). Carrefours à feux [Internet website on the design of intersections with traffic lights]. http://www.lescarrefoursafeux.fr/article.php3?id_article=9, $(07 / 14 / 2011)$.

Letirand, F., \& Delhomme, P. (2003). Augmenter la valeur prédictive de la théorie du comportement planifié par l'évaluation de plusieurs options comportementales : Une application du comportement de vitesse sur route [Increasing the predictive value of the Theory of Planned Behavior by evaluating several behavioral options: An application of the behavior of speed choice on the road]. Nouvelle Revue de Psychologie Sociale, 2(3), 319-331.

Letirand, F., \& Delhomme, P. (2005). Speed behaviour as a choice between observing and exceeding the speed limit. Transportation Research, Part F, 8, 481-492.

Letirand, F., \& Delhomme, P. (2006). Accessibilité des croyances associées aux deux options d'une alternative comportementale. Une piste à explorer pour mieux expliquer le comportement de vitesse des jeunes conducteurs? [Accessibility of beliefs associated with two options of a behavioral alternative. A possible line of approach to better explain the speeding behavior of young drivers?] Cahiers internationaux de Psychologie Sociale, 66, 3-14. 
Liang, K. Y., \& Zeger, S. L. (1986). Longitudinal data analysis using generalized linear models. Biometrika, 73(1), 13-22.

Marcovitch, S., \& Lewkowicz, D. J. (2009). Sequence learning in infancy: the independent contributions of conditional probability and pair frequency information. Developmental Science, 12(6), 1020-1025.

Ministère de l'Ecologie, de l'Energie, du Développement Durable et de la Mer. (2009). Instruction interministérielle sur la signalisation routière. http://www.securiteroutiere.gouv.fr/IMG/pdf/3-6_2009_01_IISR_6e_200908_cle27bbb8.pdf, (08/29/2011).

Ministère de l'Education nationale (2011). Official website. http://www.education.gouv.fr/cid54197/l-enseignement-dessciences.html\#Les\%20sciences\%20dans\%20les\%20enseignements\%20obligatoires, $(07 / 02 / 2011)$.

Palat, B., \& Delhomme, P. (2012). What factors can predict why drivers go through yellow traffic lights? An approach based on an extended theory of planned behavior. Safety Science, 50(3), 408-417.

Papinsky, D., Scott, D. M., \& Doherty, S. T. (2009). Exploring the route choice decisionmaking process: A comparison of planned and observed routes obtained using personbased GPS. Transportation Research Part F, 12(4), 347-358.

Peer, E. (2010). Speeding and the time-saving bias: How drivers' estimations of time saved in higher speeds affects their choice of speed. Accident Analysis and Prevention, 42, 19781982.

Pelham, B. W., Sumarta, T., \& Myaskovsky, L. (1994). The easy path from many to much: The numerosity heuristic. Cognitive Psychology, 26(2), 103-133. 
Pervin, L. A. (1963). The need to predict and control under conditions of threat. Journal of Personality, 31, 570-587.

Porter, B. E., \& Berry, T., D. (2001). A nationwide survey of self-reported red light running: measuring prevalence, predictors, and perceived consequences. Accident Analysis and Prevention, 33(6), 735-741.

Rothengatter, T. (1988). Risk and the absence of pleasure: a motivational approach to modelling road user behaviour. Ergonomics, 31(4), 599-607.

Shinar, D. (1998). Aggressive driving: the contribution of the drivers and the situation. Transportation Research Part F, 1, 137-160.

Summala, H. (1997). Hierarchical model of behavioural adaptation and traffic accidents. In: T. Rothengatter \& E. C. Vaya (Eds.), Traffic and transport psychology, theory and application, pp. 41-52, Pergamon, Amsterdam.

Sutherland, N. S. (1992). Irrationality: The enemy within. Penguin, London.

Svenson, O. (2008). Decisions among time saving options: When intuition is strong and wrong. Acta Psychologica, 127, 501-509.

Svenson, O. (2009). Driving speed changes and subjective estimates of time savings, accident risks and braking. Applied Cognitive Psychology, 23, 543-560.

Svenson, O., Eriksson, G., Salo, I., \& Peters, E. (2011). Judgments of mean speed and predictions of route choice. Transportation Research Part F, 14, 504-511.

Tenenbaum, J. B., Kemp, C., Griffiths, T. L., \& Goodman, N. D. (2011). How to grow a mind: statistics, structure, and abstraction. Science, 331(6022), 1279-1285.

Zakay, D. (2005). Attention et jugement temporel [Attention and temporal judgment]. Psychologie Française, 50, 65-79.

Zakay, D., \& Block, R. A. (1997). Temporal Cognition. Current Directions in Psychological Science, 6(1), 12-16. 
Table 1. Pairs of itineraries used in the study, corresponding to 15 hypothetical situations (durations in seconds)

Pair N

\begin{tabular}{|c|c|c|c|c|c|c|c|c|c|c|c|c|c|c|c|}
\hline & \multicolumn{1}{|c|}{$\mathbf{1}$} & $\mathbf{2}$ & $\mathbf{3}$ & $\mathbf{4}$ & $\mathbf{5}$ & $\mathbf{6}$ & $\mathbf{7}$ & $\mathbf{8}$ & $\mathbf{9}$ & $\mathbf{1 0}$ & $\mathbf{1 1}$ & $\mathbf{1 2}$ & $\mathbf{1 3}$ & $\mathbf{1 4}$ & $\mathbf{1 5}$ \\
\hline $\begin{array}{c}\text { Number of } \\
\text { traffic lights }\end{array}$ & 4 & 4 & 4 & 5 & 5 & 5 & 6 & 6 & 6 & 7 & 7 & 7 & 8 & 8 & 8 \\
\hline $\begin{array}{c}\text { Red-light } \\
\text { duration }\end{array}$ & 40 & 50 & 60 & 40 & 50 & 60 & 40 & 50 & 60 & 40 & 50 & 60 & 40 & 50 & 60 \\
\hline $\begin{array}{c}\text { Green-light } \\
\text { duration }\end{array}$ & 20 & 20 & 20 & 20 & 20 & 20 & 20 & 20 & 20 & 20 & 20 & 20 & 20 & 20 & 20 \\
\hline $\begin{array}{c}\text { Estimated mean } \\
\text { waiting time }\end{array}$ & 53.2 & 71.5 & 90.1 & 66.7 & 89.4 & 112.6 & 80 & 107.1 & 134.8 & 93.3 & 125.1 & 157.5 & 106.4 & 142.7 & 180 \\
\hline $\begin{array}{c}\text { Estimated } \\
\text { waiting time } S D\end{array}$ & 26.6 & 33.3 & 39.8 & 29.9 & 37.1 & 44.4 & 32.6 & 40.8 & 48.6 & 35.3 & 44.1 & 52.6 & 37.7 & 47 & 56.2 \\
\hline $\begin{array}{c}\text { Estimated mean } \\
\text { number of stops }\end{array}$ & 2.7 & 2.9 & 3 & 3.3 & 3.6 & 3.8 & 4 & 4.3 & 4.5 & 4.7 & 5 & 5.3 & 5.3 & 5.7 & 6 \\
\hline $\begin{array}{c}\text { Estimated } \\
\text { number of stops } \\
\text { SD }\end{array}$ & 0.9 & 0.9 & 0.9 & 1.1 & 1 & 1 & 1.2 & 1.1 & 1.1 & 1.3 & 1.2 & 1.2 & 1.3 & 1.3 & 1.2 \\
\hline $\begin{array}{c}\text { Number of } \\
\text { traffic lights }\end{array}$ & 12 & 12 & 12 & 12 & 12 & 12 & 12 & 12 & 12 & 12 & 12 & 12 & 12 & 12 & 12 \\
\hline $\begin{array}{c}\text { Red-light } \\
\text { duration }\end{array}$ & 20 & 20 & 20 & 20 & 20 & 20 & 20 & 20 & 20 & 20 & 20 & 20 & 20 & 20 & 20 \\
\hline $\begin{array}{c}\text { Green-light } \\
\text { duration }\end{array}$ & 40 & 50 & 60 & 40 & 50 & 60 & 40 & 50 & 60 & 40 & 50 & 60 & 40 & 50 & 60 \\
\hline $\begin{array}{c}\text { Estimated mean } \\
\text { waiting time }\end{array}$ & 80 & 85.5 & 89.9 & 80.2 & 86 & 89.8 & 79.9 & 86 & 90.1 & 79.9 & 85.8 & 90 & 80 & 85.7 & 89.9 \\
\hline $\begin{array}{c}\text { Estimated } \\
\text { waiting time } S D\end{array}$ & 40.2 & 47.2 & 54.1 & 40.2 & 47.4 & 54.1 & 40.1 & 47.4 & 54 & 39.8 & 47.2 & 54.2 & 40.1 & 47.3 & 54.1 \\
\hline $\begin{array}{c}\text { Estimated mean } \\
\text { number of stops }\end{array}$ & 4 & 3.4 & 3 & 4 & 3.4 & 3 & 4 & 3.4 & 3 & 4 & 3.4 & 3 & 4 & 3.4 & 3 \\
\hline $\begin{array}{c}\text { Estimated } \\
\text { number of stops } \\
\text { SD }\end{array}$ & 1.6 & 1.6 & 1.5 & 1.6 & 1.6 & 1.5 & 1.6 & 1.6 & 1.5 & 1.6 & 1.6 & 1.5 & 1.6 & 1.6 & 1.5 \\
\hline
\end{tabular}


Table 2. Descriptive statistics of self-reported measures used in the analyses

\begin{tabular}{|l|l|l|}
\hline Item & $\boldsymbol{M}$ & $\boldsymbol{S D}$ \\
\hline Frequency of planning alternative itineraries before taking the wheel & 3.17 & 1.35 \\
\hline Frequency of planning alternative itineraries while driving a car & 2.59 & 1.36 \\
\hline Frequency of using the number of traffic lights as a criterion for route choice & 2.19 & 1.33 \\
\hline Frequency of using red- and green-light durations at traffic lights as a route-choice criterion & 1.86 & 1.22 \\
\hline Yellow lights run during the month prior to the study & 4.2 & 3.39 \\
\hline Red lights run during the month prior to the study & 0.7 & 0.72 \\
\hline Frequency of abiding by speed limits on different types of roads & 3.77 & 0.97 \\
\hline
\end{tabular}


Table 3. Three probability estimates used to judge participants' preferences in route choice. Over a white background: pairs where optimal choices were most probable. Over a light grey background: pairs where choices reflect the numerosity heuristic but are little likely to bring about non-optimal choices. Over a dark grey background: pairs where choices reflect the numerosity heuristic and are quite likely to bring about nonoptimal choices.

Pair N

\begin{tabular}{|c|c|c|c|c|c|c|c|c|c|c|c|c|c|c|c|c|}
\hline & & 1 & 2 & 3 & 4 & 5 & 6 & 7 & 8 & 9 & 10 & 11 & 12 & 13 & 14 & 15 \\
\hline \multicolumn{17}{|c|}{ Estimate from GEE model } \\
\hline \multirow{3}{*}{$\begin{array}{c}\text { Probabi } \\
\text { lity of } \\
\text { choosin } \\
\mathrm{g} \text { an } \\
\text { itinerar } \\
\text { y with } \\
\text { fewer } \\
\text { traffic } \\
\text { lights }\end{array}$} & $\begin{array}{c}\text { upp } \\
\text { er } \\
\text { bou } \\
\text { nd }\end{array}$ & $\begin{array}{c}0.9 \\
5\end{array}$ & $\begin{array}{c}0.8 \\
9\end{array}$ & $\begin{array}{c}0.8 \\
4\end{array}$ & $\begin{array}{c}0.9 \\
2\end{array}$ & $\begin{array}{c}0.8 \\
2\end{array}$ & $\begin{array}{c}0.6 \\
2\end{array}$ & 0.8 & $\begin{array}{c}0.6 \\
3\end{array}$ & $\begin{array}{c}0.4 \\
8\end{array}$ & $\begin{array}{c}0.6 \\
7\end{array}$ & $\begin{array}{c}0.4 \\
6\end{array}$ & 0.4 & $\begin{array}{c}0.5 \\
3\end{array}$ & $\begin{array}{c}0.3 \\
3\end{array}$ & $\begin{array}{c}0.3 \\
1\end{array}$ \\
\hline & & $\begin{array}{c}0.9 \\
2\end{array}$ & $\begin{array}{c}0.8 \\
5\end{array}$ & $\begin{array}{c}0.7 \\
8\end{array}$ & $\begin{array}{c}0.8 \\
8\end{array}$ & $\begin{array}{c}0.7 \\
6\end{array}$ & $\begin{array}{c}0.5 \\
5\end{array}$ & $\begin{array}{c}0.7 \\
4\end{array}$ & $\begin{array}{c}0.5 \\
6 \\
\end{array}$ & $\begin{array}{c}0.4 \\
1\end{array}$ & 0.6 & $\begin{array}{c}0.3 \\
9\end{array}$ & $\begin{array}{c}0.3 \\
4\end{array}$ & $\begin{array}{c}0.4 \\
6\end{array}$ & $\begin{array}{c}0.2 \\
7\end{array}$ & $\begin{array}{c}0.2 \\
5\end{array}$ \\
\hline & $\begin{array}{l}\text { low } \\
\text { er } \\
\text { bou } \\
\text { nd }\end{array}$ & $\begin{array}{c}0.8 \\
7\end{array}$ & $\begin{array}{c}0.7 \\
9\end{array}$ & $\begin{array}{c}0.7 \\
2\end{array}$ & $\begin{array}{c}0.8 \\
3\end{array}$ & 0.7 & $\begin{array}{c}0.4 \\
8\end{array}$ & $\begin{array}{c}0.6 \\
8\end{array}$ & $\begin{array}{c}0.4 \\
9\end{array}$ & $\begin{array}{c}0.3 \\
5\end{array}$ & $\begin{array}{c}0.5 \\
3\end{array}$ & $\begin{array}{c}0.3 \\
2\end{array}$ & $\begin{array}{c}0.2 \\
7\end{array}$ & $\begin{array}{c}0.3 \\
9\end{array}$ & $\begin{array}{c}0.2 \\
1\end{array}$ & $\begin{array}{c}0.1 \\
9\end{array}$ \\
\hline
\end{tabular}

Estimates from predicted relative frequency obtained by simulation

\begin{tabular}{|c|c|c|c|c|c|c|c|c|c|c|c|c|c|c|c|c|}
\hline \multirow{3}{*}{$\begin{array}{l}\text { Probabi } \\
\text { lity that } \\
\text { the } \\
\text { waiting } \\
\text { time for } \\
\text { the } \\
\text { itinerar } \\
\text { y with } \\
\text { fewer } \\
\text { traffic } \\
\text { lights } \\
\text { would } \\
\text { be } \\
\text { shorter }\end{array}$} & $\begin{array}{c}\text { upp } \\
\text { er } \\
\text { bou } \\
\text { nd } \\
\end{array}$ & 0.7 & $\begin{array}{c}0.5 \\
8\end{array}$ & $\begin{array}{c}0.4 \\
8\end{array}$ & 0.6 & $\begin{array}{c}0.4 \\
7\end{array}$ & $\begin{array}{c}0.3 \\
6\end{array}$ & $\begin{array}{c}0.4 \\
9\end{array}$ & $\begin{array}{c}0.3 \\
6\end{array}$ & $\begin{array}{c}0.2 \\
7\end{array}$ & 0.4 & $\begin{array}{c}0.2 \\
7\end{array}$ & $\begin{array}{c}0.1 \\
9\end{array}$ & $\begin{array}{c}0.3 \\
1\end{array}$ & 0.2 & $\begin{array}{c}0.1 \\
3\end{array}$ \\
\hline & & 0.7 & $\begin{array}{c}0.5 \\
8 \\
\end{array}$ & $\begin{array}{c}0.4 \\
8\end{array}$ & $\begin{array}{c}0.5 \\
9\end{array}$ & $\begin{array}{c}0.4 \\
7\end{array}$ & $\begin{array}{c}0.3 \\
6\end{array}$ & $\begin{array}{c}0.4 \\
9\end{array}$ & $\begin{array}{c}0.3 \\
6 \\
\end{array}$ & $\begin{array}{c}0.2 \\
6\end{array}$ & $\begin{array}{c}0.3 \\
9\end{array}$ & $\begin{array}{c}0.2 \\
7\end{array}$ & $\begin{array}{c}0.1 \\
9\end{array}$ & $\begin{array}{c}0.3 \\
1\end{array}$ & 0.2 & $\begin{array}{c}0.1 \\
3\end{array}$ \\
\hline & $\begin{array}{l}\text { low } \\
\text { er } \\
\text { bou } \\
\text { nd }\end{array}$ & 0.7 & $\begin{array}{c}0.5 \\
8\end{array}$ & $\begin{array}{c}0.4 \\
8\end{array}$ & $\begin{array}{c}0.5 \\
9\end{array}$ & $\begin{array}{c}0.4 \\
6\end{array}$ & $\begin{array}{c}0.3 \\
6\end{array}$ & $\begin{array}{c}0.4 \\
9\end{array}$ & $\begin{array}{c}0.3 \\
6\end{array}$ & $\begin{array}{c}0.2 \\
6\end{array}$ & $\begin{array}{c}0.3 \\
9\end{array}$ & $\begin{array}{c}0.2 \\
7\end{array}$ & $\begin{array}{c}0.1 \\
8\end{array}$ & $\begin{array}{c}0.3 \\
1\end{array}$ & $\begin{array}{c}0.1 \\
9\end{array}$ & $\begin{array}{c}0.1 \\
2\end{array}$ \\
\hline $\begin{array}{l}\text { Estimat } \\
\text { ed } \\
\text { probabi } \\
\text { litv that }\end{array}$ & $\begin{array}{c}\text { upp } \\
\text { er } \\
\text { bou } \\
\text { nd } \\
\end{array}$ & $\begin{array}{c}0.8 \\
4\end{array}$ & $\begin{array}{c}0.7 \\
1\end{array}$ & 0.6 & $\begin{array}{c}0.7 \\
2\end{array}$ & $\begin{array}{c}0.5 \\
6\end{array}$ & $\begin{array}{c}0.4 \\
3\end{array}$ & $\begin{array}{c}0.5 \\
9\end{array}$ & $\begin{array}{c}0.4 \\
1\end{array}$ & $\begin{array}{c}0.2 \\
9\end{array}$ & $\begin{array}{c}0.4 \\
6\end{array}$ & $\begin{array}{c}0.2 \\
9\end{array}$ & $\begin{array}{c}0.1 \\
8\end{array}$ & $\begin{array}{c}0.3 \\
4\end{array}$ & $\begin{array}{c}0.1 \\
9\end{array}$ & 0.1 \\
\hline $\begin{array}{l}\text { the } \\
\text { number }\end{array}$ & & $\begin{array}{c}0.8 \\
3 \\
\end{array}$ & $\begin{array}{c}0.7 \\
1\end{array}$ & $\begin{array}{c}0.5 \\
9 \\
\end{array}$ & $\begin{array}{c}0.7 \\
2 \\
\end{array}$ & $\begin{array}{c}0.5 \\
6 \\
\end{array}$ & $\begin{array}{c}0.4 \\
2 \\
\end{array}$ & $\begin{array}{c}0.5 \\
9\end{array}$ & $\begin{array}{c}0.4 \\
1\end{array}$ & $\begin{array}{c}0.2 \\
8 \\
\end{array}$ & $\begin{array}{c}0.4 \\
6 \\
\end{array}$ & $\begin{array}{c}0.2 \\
9 \\
\end{array}$ & $\begin{array}{c}0.1 \\
8\end{array}$ & $\begin{array}{c}0.3 \\
4 \\
\end{array}$ & $\begin{array}{c}0.1 \\
9 \\
\end{array}$ & 0.1 \\
\hline $\begin{array}{l}\text { of stops } \\
\text { along } \\
\text { the } \\
\text { itinerar } \\
\text { y with } \\
\text { fewer } \\
\text { traffic } \\
\text { lights } \\
\text { would } \\
\text { be } \\
\text { lower }\end{array}$ & $\begin{array}{c}\text { low } \\
\text { er } \\
\text { bou } \\
\text { nd }\end{array}$ & $\begin{array}{l}0.8 \\
3\end{array}$ & $\begin{array}{l}0.7 \\
1\end{array}$ & $\begin{array}{l}0.5 \\
9\end{array}$ & $\begin{array}{l}0.7 \\
2\end{array}$ & $\begin{array}{l}0.5 \\
6\end{array}$ & $\begin{array}{l}0.4 \\
2\end{array}$ & $\begin{array}{l}0.5 \\
9\end{array}$ & $\begin{array}{l}0.4 \\
1\end{array}$ & $\begin{array}{l}0.2 \\
8\end{array}$ & $\begin{array}{l}0.4 \\
5\end{array}$ & $\begin{array}{l}0.2 \\
8\end{array}$ & $\begin{array}{l}0.1 \\
7\end{array}$ & $\begin{array}{l}0.3 \\
4\end{array}$ & $\begin{array}{l}0.1 \\
9\end{array}$ & 0.1 \\
\hline
\end{tabular}

